\title{
RagaM BaHASA pada tUTURAN pEDAGaNG IKAN KABUPATEN DEMAK DITINJAU DARI KAJIAN FONOLOGI RIFQIANA AZIZAH', TURAHMAT ${ }^{2}$, dan OKTARINA PUSPITA WARDANI ${ }^{3}$ \\ Prodi PBSI, FKIP Universitas Islam Sultan Agung \\ lintangsastra@unissula.ac.id²,oktarinapw@unissula.ac.id³
}

Pertama Diterima: 22 Mei 2017

Bukti Akhir Diterima: 06 Juni 2017

\begin{abstract}
Abstrak
Masyarakat indonesia memiliki banyak suku sehingga banyak ragam bahasa yang digunakan. Hal itu terjadi karena banyak budaya yang dipakai di masyarakat. Ragam bahasa pedagang ikan juga memiliki variasi bahasa tersendiri sehingga bisa dibedakan dnegan pedangan lainnya. Hal itu tampak ketika pedagang menjajakan dagangannya. Ragam bahasa ditinjau dari segi fonologi mampu menafsirkan penambahan, penurangan maupun perubahan fonem. Tuturan pedagang ikan di pasar Demak memiliki ciri khas masing-masing. Keragaman itulah yang menjadi daya tarik dalam penelitian ini. Tujuan dalam penelitian ini ialah mampu mendeskripsikan ujaran pedagang ikan di Kabupaten Demak berdasarkan kajian fonologi. Metode yang digunakan ialah metode kualitatif deskripsi. Metode yang tidak membutuhkan hitungan angka. Data dan sumber data yang dibutuhkan dalam penelitian ini berupa kata, frasa, kalimat dalam tuturan pedagang ikan di Kabupaten Demak. hasil penelitian menjabarkan ragam bahasa dari pedagang ikan yang ditinjau dari kajian fonologi. Terdapat perubahan fonem (agar pembeli mendengar dengan jelas ikan yang ditawarkan pedagang), penghilangan fonem (agar pedagang cepat menyampaikan tuturan untuk menjajakan dagangannya), dan penambahan fonem (untuk kelancaran pedagang dalam bertutur) sehingga tujuan pedagang dalam menjajakan ikan dapat diterima oleh pembeli.
\end{abstract}

Kata kunci: ragam bahasa, fonologi

\begin{abstract}
Indonesian people have so many tribes that various language are used. It happens for many cultures growing around citizens. Various language used by fishmongers also have unique varieties that could be distinguished from other sellers. It could be seen when they sell their goods. Language variety viewed from phonology aspect could interpret phoneme addition, reduction or change. Fishmongers' speech in Demak market have their own unique characteristics. These varieties were the attractions of this research. Purpose of this research was to describe fishmongers' speech in Demak Regency based on phonologic study. The used method was qualitative description method which do not need numbers. Data needed by this research were in forms of words, phrases, sentences and speeches of fishmongers in Demak Regency. Result of the study described language variety as viewed from phonologic study. There were phoneme change (to make buyers clearly heard what fish was being offered), phoneme reduction (to make sellers quickly delivered speech to offer their fish to buyers), and phoneme addition (to ease fishmongers to deliver speech) so that fishmongers' aim to sell their fish could be accepted by the buyers.
\end{abstract}

Keywords: language variety, phonology 


\section{PENDAHULUAN}

Ragam atau variasi bahasa adalah bentuk atau wujud bahasa yang ditandai oleh ciri-ciri linguistik tertentu, seperti fonologi, morfologi, dan sintaksis. Di samping ditandai oleh ciriciri linguistik, timbulnya ragam bahasa juga ditandai oleh ciri-ciri nonlinguistic, misalnya, lokasi atau tempat penggunaannya, lingkungan sosial pemakaiannya, dan lingkungan keprofesian pemakai bahasa yang bersangkutan.

Ragam bahasa atau variasi bahasa tersebut dapat dilihat pada pedagang ikan di TPI (tempat pelelangan ikan). Berkomunikasi dengan pembeli ikan sesama daerah maupun luar daerah. Tanpa berkomunikasi yang baik ikan dagangan tersebut tidak akan mudah terjual. Dimana pedagang ikan harus pandai cara berbahasa untuk meyakinkan si pembeli, merayu, cara berbahasa dengan nada serius, dan lain sebagainya.

Masyarakat yang beraneka ragam serta lingkungan budaya yang berbeda menimbulkan ragam bahasa dalam penggunaan bahasa. Ragam bahasa dalam penggunaan bahasa merupakan suatu keberadaan tidak seragamnya bahasa yang ada dalam masyarakat. Munculnya ragam bahasa disebabkan adanya kebutuhan penggunaan bahasa untuk berkomunikasi dan bekerjasama sesuai dengan situasi dan fungsi dalam kontak sosialnya. Setiap penutur bahasa, hidup dalam latar belakang dan tata cara pergaulan yang berbedabeda. Orang yang ingin turut serta dalam membicarakan sebuah topik masalah tertentu, memiliki ragam bahasa tersendiri antara satu orang dengan orang lain untuk berkomunikasi dan berinteraksi.

Terdapat dua pandangan mengenai variasi bahasa, pertama variasi berdasarkan penutur bahasa, kedua variasi bahasa berdasarkan fungsi dalam masyarakat. Penutur yang homogen, etnis, status sosial sama berarti bahasa itu akan menjadi seragam. Sebaliknya, jika masyarakat beraneka ragam bahasa akan berbeda-beda sesuai dengan fungsinya untuk berinteraksi dalam masyarakat (Chaer dan Agustin, 2004).

Ragam variasi bahasa yang digunakan pedagang ikan di TPI Kecamatan Wedung, Kabupaten Demak dapat dicontohkan sebagai berikut: (1). Varian fonologi contoh : Dengbandeng (bandeng-bandeng) Pengucapan bunyi yang dihasilkan pedagang asongan satu dengan yang lain memiliki ciri khas yang berbeda walaupun barang yang mereka jual sama. (2). Varian morfologi contoh : Bandeng selawe sekilo / bandeng $251 \mathrm{~kg}$ (bandeng $1 \mathrm{~kg}$ harga 25 ribu).

Chaer (2009, hal 1) mengungkapkan arti fonologi secara etimologi ialah fon yang berarti "bunyi", dan logi yang berarti "ilmu”. Fonologi merupakan cabang ilmu linguistik yang membahas dan menganalisis bunyi bahasa dari alat ucap manusia. Bunyi bahasa sebagai 
satuan terkecil dari ujaran dan gabungan antarbunyi yang membentuk silabel, serta unsur suprasegmental. Ciri fonologi menyangkut bunyi bahasa, baik ciri-cirinya maupun fungsinya dalam suatu bahasa. Tuturan pedagang ikan ditandai dengan adanya gejala-gejala bahasa, serta cenderung memakai dialek.

Pada waktu menjajakan barang dagangannya, para pedagang ikan menunjukkan ciri khusus yang membedakan dengan pedagang lainnya. Ciri khusus itu tampak pada cara dan strategi mereka berbahasa yang lebih sering menggunakan kata-kata tertentu yang diulangulang, walaupun terkadang pengulangan kata tersebut tidak perlu. Ragam bahasa yang dipakai pedagang ikan saat mereka menjajakan barangnya disebut ragam usaha

Peneliti membahas ragam bahasa pedagang ikan di TPI Kecamatan Wedung, Kabupaten Demak yaitu: Pertama, karakteristik atau ciri khas kata yang dihasilkan pedagang ikan saat mereka menawarkan barang, lebih unik dan menarik untuk diteliti. Kedua, keragaman dalam pengucapan kata oleh pedagang ikan menimbulkan tuturan yang berbeda sehingga akan memperkaya ragam bahasa.

\section{METODE PENELITIAN}

Metode yang digunakan ialah metode kualitatif deskriptif. Penelitian kualitatif merupakan jenis penelitian yang hasil penelitiannya tidak dari hasil statistik maupun dari hitungan lain (Basrowi dan Suwandi, 2008, hal 21). Data penelitian ialah tuturan berupa kata, frase, klausa, dan kalimat. Sumber data pedagang ikan di pasar Demak.

Sebuah penelitian memerlukan intrumen penelelitian sebagai alat ukur dalam penelitian. Sugiyono (2012) menyatakan prinsip melakukan penelitian ialah melakukan penelitian, sehingga diperlukan alat ukur yang sesuai. Intrumen dalam peneltian ini menggunakan alat rekam, lembar wawancara dan kartu kata.

Teknik pengumpulan data menggunakan teknik rekam, simak, dan catat. Teknik rekam digunakakan ketika pedagang menawarkan barangnya kepada pembeli.Teknik simak digunakan untuk menyimak percakapan yang telah direkam untuk menemukan ragam bahasa yang digunakan pedagang. Teknik catat digunakan untuk mengelompokkan hasil wawancara dengan pedagang.

Analisis data pada penelitian ini menggunakan analisis deskriptif. Data yang diperoleh dianalisis kemudian dideskripsikan dan dihubungkan dnegan teori yang ada. Terdapat dua tahap dalam analisi data. Tahap tersebut ialah persiapan dan pengelompokan data. 


\section{HASIL PENELITIAN DAN PEMBAHASAN}

Pedagang ikan saat menjajakan ikan dagangannya menunjukkan adanya perubahan fonem, penghilangan fonem, dan penambahan fonem. Ketiga hal tersebut akan dipaparkan sebagai berikut.

\section{Perubahan Fonem}

Perubahan fonem berdasarkan ciri fonologi merupakan berubahnya bunyi atau fonem pada sebuah kata agar kata menjadi terdengar dengan jelas atau untuk tujuan tertentu. Perubahan fonem terlihat dalam segmen tutur berikut.

\section{$\mathrm{Pj}$ : "Mujaer mbak, mujaer"}

Kata "mujair" terjadi perubahan fonem bunyi vokal [i] menjadi bunyi vokal [e], sehingga kata "mujair" menjadi kata "mujaer". Proses perubahan fonem dari kata "mujair" menjadi kata "mujaer" disebut proses netralisasi karena terjadi perubahan fonem akibat pengaruh lingkungan.

$$
\begin{gathered}
\mathrm{Pj} \quad \text { : "Mujaere mbak." } \\
\text { (mujaernya mbak) }
\end{gathered}
$$

Kata "mujair" terjadi perubahan fonem bunyi vokal [i] menjadi bunyi vokal [e], sehingga kata "mujair” menjadi kata "mujaer". Proses perubahan fonem dari kata "mujair" menjadi kata "mujaer" disebut proses netralisasi karena terjadi perubahan fonem akibat pengaruh lingkungan.

$$
\begin{gathered}
\mathrm{Pb}: \text { "Duwe iwak opo, mbak?" } \\
\text { (punya ikan apa, mbak?) } \\
\mathrm{Pj} \text { : "Wak patel, mbak" } \\
\text { (ikan patel, mbak) }
\end{gathered}
$$

Kata "patel" terjadi perubahan fonem bunyi vokal [i] menjadi bunyi vokal [e], sehingga kata "patil" menjadi kata "patel". Proses perubahan fonem dari kata "patil" menjadi kata "patel" disebut proses netralisasi karena terjadi perubahan fonem akibat pengaruh lingkungan.

$$
\begin{gathered}
\mathrm{Pj} \text { : "Wes kunu bayaro kabeh, molas lah." } \\
\text { (dah situ bayar semua, lima belas lah) } \\
\mathrm{Pb} \text { : "Yo wes-yo wes kene." }
\end{gathered}
$$


(yaudah-yaudah sini)

Kata "wes" terjadi perubahan fonem bunyi vokal [i] menjadi bunyi vokal [e], sehingga kata "wis" menjadi kata "wes". Proses perubahan fonem dari kata "wis" menjadi kata "wes" disebut proses netralisasi karena terjadi perubahan fonem akibat pengaruh lingkungan.

$$
\begin{gathered}
\mathrm{Pj} \text { : "Golek opo mbak? kijeng, mbak." } \\
\text { (cari apa mbak? Kijeng, mbak.) } \\
\text { Pb1: "Mboten riyen." }
\end{gathered}
$$

(Tidak dulu)

Kata "kijeng" terjadi perubahan fonem bunyi vokal [i] menjadi bunyi vokal [e], sehingga kata "kijing” menjadi kata "kijeng”. Proses perubahan fonem dari kata "kijing" menjadi kata "kijeng" disebut proses netralisasi karena terjadi perubahan fonem akibat pengaruh lingkungan.

Pb1: "Opo iku mbak kok mbok tutupi?" (apa itu mbak kok di tutupi?)

$\mathrm{Pj}$ : "Piteng mbak. Iki yo ono kerang, opo kijeng."

(Piteng, mbak. Ini juga ada kerang, apa kijeng.)

Kata "piteng" terjadi perubahan fonem bunyi vokal [i] menjadi bunyi vokal [e], sehingga kata "piting” menjadi kata "piteng". Proses perubahan fonem dari kata "piting" menjadi kata "piteng" disebut proses netralisasi karena terjadi perubahan fonem akibat pengaruh lingkungan.

Kata "kijeng" terjadi perubahan fonem bunyi vokal [i] menjadi bunyi vokal [e], sehingga kata "kijing" menjadi kata "kijeng”. Proses perubahan fonem dari kata "kijing" menjadi kata "kijeng" disebut proses netralisasi karena terjadi perubahan fonem akibat pengaruh lingkungan.

Pj : "Seket limo isi limo. Sewidak limo isi papat. Pitong puloh isi telu." (Lima puluh lima. Enam puluh lima isi empat. Tujuh puluh isi tiga)

Pb1: "Keono seng seket limo wae."

(kasih yang lima puluh lima saja)

Kata "pitong puloh" terjadi perubahan fonem bunyi vokal [u] menjadi bunyi vokal [o], sehingga kata "pitung puluh" menjadi kata "pitong puloh". Proses perubahan fonem dari kata 
"pitung puluh" menjadi kata "pitong puloh" disebut proses netralisasi karena terjadi perubahan fonem akibat pengaruh lingkungan.

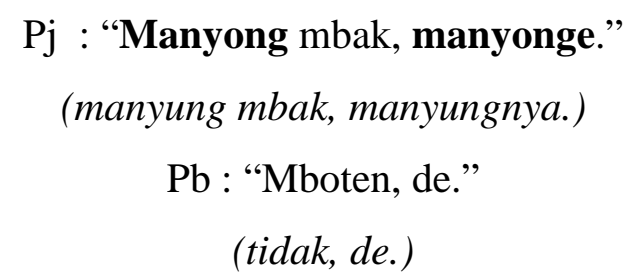

Kata "manyong" terjadi perubahan fonem bunyi vokal $[\mathrm{u}]$ menjadi bunyi vokal $[\mathrm{o}]$, sehingga kata "manyung" menjadi kata "manyong”. Proses perubahan fonem dari kata “manyung” menjadi kata "manyong” disebut proses netralisasi karena terjadi perubahan fonem akibat pengaruh lingkungan.

$\mathrm{Pj}$ : "Kembong tukuno molas wae, sek seger-seger ngene. Mboh pirang kilo iki. Sek akeh ngene og."

(Kembung lima belas saja. Segar-segar. Banyak ini)

$\mathrm{Pb}$ : "Halah ngene sek akeh, iki paling gur sekilo tok. Sepuloh neg gelem, de."

(halah gini kok banyak, ini paling cuman satu kilo aja. Sepuluh kalau mau.)

Kata "kembong" terjadi perubahan fonem bunyi vokal [u] menjadi bunyi vokal [o], sehingga kata "kembung" menjadi kata "kembong". Proses perubahan fonem dari kata “kembung” menjadi kata "kembong” disebut proses netralisasi karena terjadi perubahan fonem akibat pengaruh lingkungan.

Kata "mboh" terjadi perubahan fonem bunyi vokal $[\mathrm{u}]$ menjadi bunyi vokal [o], sehingga kata "mbuh" menjadi kata "mboh". Proses perubahan fonem dari kata " $m b u h$ " menjadi kata "mboh" disebut proses netralisasi karena terjadi perubahan fonem akibat pengaruh lingkungan.

Kata "sepuloh" terjadi perubahan fonem bunyi vokal [u] menjadi bunyi vokal [o], sehingga kata "sepuluh" menjadi kata "sepuloh". Proses perubahan fonem dari kata "sepuluh" menjadi kata "sepuloh" disebut proses netralisasi karena terjadi perubahan fonem akibat pengaruh lingkungan.

Pb1: "De, nuse pintenan?"

(de, cuminya berapaan?)

$\mathrm{Pj}$ : "Nus ngendok nduk, sewidak wae, seng rak ngendok yo seket limo. Gur limangewu tok lo." 
(Cumi bertelur dek enam puluh saja, yang tidak bertelur lima puluh lima. Cuman lima ribu saja lho.)

Kata "seng" terjadi perubahan fonem bunyi vokal [i] menjadi bunyi vokal [e], sehingga kata "sing" menjadi kata "seng". Proses perubahan fonem dari kata "sing" menjadi kata "seng” disebut proses netralisasi karena terjadi perubahan fonem akibat pengaruh lingkungan.

Kata "ngendok" terjadi perubahan fonem bunyi vokal [k] menjadi bunyi vokal [g], sehingga kata "ngendhog" menjadi kata "ngendok". Proses perubahan fonem dari kata "ngendhog" menjadi kata "ngendok" disebut proses netralisasi karena terjadi perubahan fonem akibat pengaruh lingkungan.

Pj : "Iki gurita, iki totok, seng iki sotong."

(Ini gurita, ini totok, yang ini sotong.)

Pb1: "Seng boten ngendog mawon lah, artone kirang og, paringi kaleh kilo."

(Yang tidak bertelur saja lah, uangnya kurang, kasih dua kilo saja.)

Kata "seng" terjadi perubahan fonem bunyi vokal [i] menjadi bunyi vokal [e], sehingga kata "sing" menjadi kata "seng". Proses perubahan fonem dari kata "sing" menjadi kata "seng" disebut proses netralisasi karena terjadi perubahan fonem akibat pengaruh lingkungan.

$\mathrm{Pj}$ : "Wes pas, pak. Iki lho mbake nek tuku gak tau ngenyang wes reti regone mungggah medun semonten. Nek pengen murah iki nus totok pak, rong puloh. Rasane nggeh sami kok."

(Sudah pas, pak. Ini lho mbaknya kalau beli tidak pernah menawar, sudah tahu harganya naik turun segitu. Kalau mau murah ini nus totok pak, dua puluh. Rasanya juga sama saja

$$
\text { kok.) }
$$

$\mathrm{Pb} 2$ : "Seng iku sekilo seng biasa iki sekilo ya, mbak."

(yang itu satu kilo yang biasa satu kilo ya, mbak.)

Kata "wes" terjadi perubahan fonem bunyi vokal [i] menjadi bunyi vokal [e], sehingga kata "wis" menjadi kata "wes". Proses perubahan fonem dari kata "wis" menjadi kata "wes" disebut proses netralisasi karena terjadi perubahan fonem akibat pengaruh lingkungan.

Kata "nggeh" terjadi perubahan fonem bunyi vokal [i] menjadi bunyi vokal [e], sehingga kata "nggih" menjadi kata "nggeh". Proses perubahan fonem dari kata "nggih" 
menjadi kata "nggeh" disebut proses netralisasi karena terjadi perubahan fonem akibat pengaruh lingkungan.

$\mathrm{Pj}$ : "Bloso, mbak."

$\mathrm{Pb}$ : "Lah kok sitek ngunu."

(kok sedikit gitu)

$\mathrm{Pj}$ : "Bloso sitek tok iki, gowono nyoh mbak, wolongewu wae lah, gak sah ngenyang meneh."

(bloso sedikit saja ini, bawa saja mbak, delapan ribu, tidak usah menawar)

Kata "wolongewu" terjadi perubahan fonem bunyi vokal $[\mathrm{u}]$ menjadi bunyi vokal [o], sehingga kata "wolungewu” menjadi kata "wolongewu”. Proses perubahan fonem dari kata "wolungewu" menjadi kata "wolongewu" disebut proses netralisasi karena terjadi perubahan fonem akibat pengaruh lingkungan. Proses netralisasi karena terjadi perubahan fonem akibat pengaruh lingkungan.

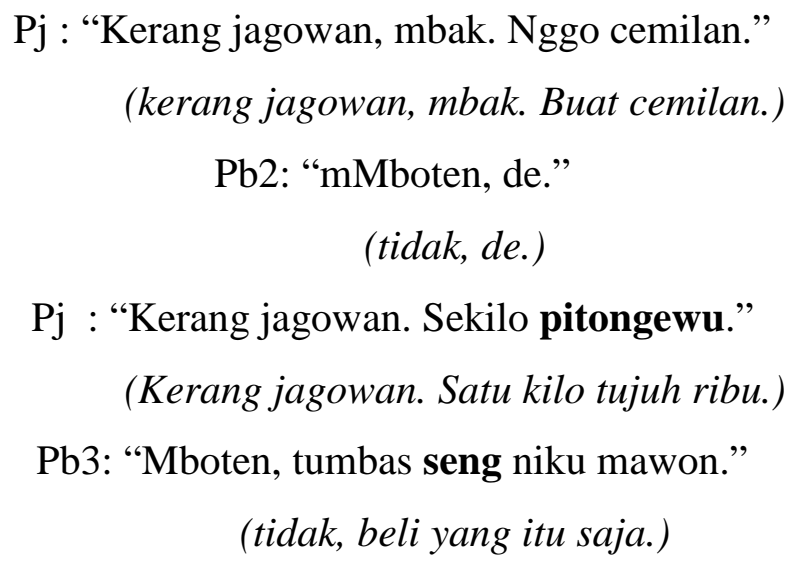

Kata "seng" terjadi perubahan fonem bunyi vokal [i] menjadi bunyi vokal [e], sehingga kata "sing" menjadi kata "seng". Proses perubahan fonem dari kata "sing" menjadi kata "seng" disebut proses netralisasi karena terjadi perubahan fonem akibat pengaruh lingkungan.

Kata "pitongewu" terjadi perubahan fonem bunyi vokal [u] menjadi bunyi vokal [o], sehingga kata "pitungewu" menjadi kata "pitongewu”. Proses perubahan fonem dari kata "pitungewu" menjadi kata "pitongewu" disebut proses netralisasi karena terjadi perubahan fonem akibat pengaruh lingkungan.

Pj : "Panggange nduk, seger-seger iku lagek distori iki mau. Telongewu nduk, kyok biasane. Ndaging lo delokono.” 
(Panggangnya dek, segar-segar, itu baru di setori ini tadi. Tiga ribu, dek seperti biasanya, daging itu.)

$\mathrm{Pb}$ : "Dikirangi, de."

(Dikurangi, de.)

Kata "telongewu" terjadi perubahan fonem bunyi vokal $[\mathrm{u}]$ menjadi bunyi vokal [o], sehingga kata "telungewu" menjadi kata "telongewu". Proses perubahan fonem dari kata "telungewu" menjadi kata "telongewu" disebut proses netralisasi karena terjadi perubahan fonem akibat pengaruh lingkungan.

\section{Pengurangan Fonem}

Pengurangan fonem berdasarkan ciri fonologi merupakan hilangnya bunyi atau fonem pada awal, tengah dan akhir sebuah kata tanpa mengubah makna. Penghilangan ini biasanya berupa pemendekan kata. Penghilangan fonem terlihat dalam segmen tutur berikut.

$$
\begin{gathered}
\mathrm{Pb}: \text { "Duwe iwak opo, mbak?" } \\
\text { (punya ikan apa, mbak?) } \\
\mathrm{Pj}: \text { "Wak patel, mbak" } \\
\text { (ikan patel, mbak) }
\end{gathered}
$$

Kata "wak" terjadi pengurangan fonem bunyi vokal [i] sehingga kata "iwak" dilafalkan "wak". Proses penghilangan fonem vokal [i] pada kata "iwak" menjadi "wak"disebut proses aferesis, karena pada kata "iwak" terjadi proses pengurangan fonem pada awal kata.

$$
\begin{array}{r}
\mathrm{Pb}: \text { "Emm rak ono campurane iwak liyo?" } \\
\text { (tidak ada campurannya ikan lain?) } \\
\mathrm{Pj} \quad \text { : "Garek iki og." } \\
\text { (tinggal ini saja) }
\end{array}
$$

Kata "rak" terjadi pengurangan fonem bunyi vokal [o] sehingga kata "orak" dilafalkan "rak". Proses penghilangan fonem vokal [o] pada kata "orak" menjadi "rak"disebut proses aferesis, karena pada kata "orak" terjadi proses pengurangan fonem pada awal kata.

$$
\begin{array}{r}
\mathrm{Pj} \text { : "Wes kunu bayaro kabeh, molas lah." } \\
\text { (dah situ bayar semua, lima belas lah) }
\end{array}
$$




$$
\begin{array}{r}
\mathrm{Pb}: \text { "Yo wes-yo wes kene." } \\
\text { (yaudah-yaudah sini) }
\end{array}
$$

Kata "molas" terjadi pengurangan fonem bunyi vokal [1] dan [i] sehingga kata "limolas" dilafalkan "molas". Proses penghilangan fonem vokal [1] dan [i] pada kata "limolas" menjadi "molas"disebut proses aferesis, karena pada kata "orak" terjadi proses pengurangan fonem pada awal kata.

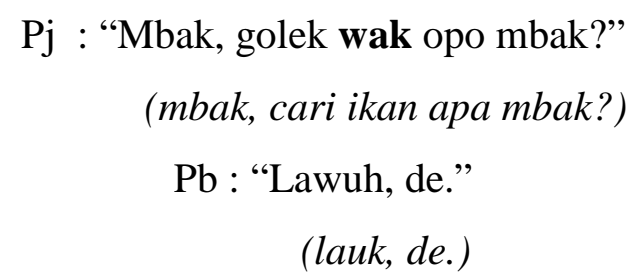

Kata "wak" terjadi pengurangan fonem bunyi vokal [i] sehingga kata "iwak" dilafalkan "wak". Proses penghilangan fonem vokal [i] pada kata "iwak" menjadi "wak"disebut proses aferesis, karena pada kata "iwak" terjadi proses pengurangan fonem pada awal kata.

\section{$\mathrm{Pj}$ : "Tambaono rongewu tak wadahake."}

(Tambahi dua ribu saya bungkuskan)

$\mathrm{Pb}$ : "Yo kene diwadahi." (ya sini bungkuskan)

Kata "tambaono" terjadi pengurangan fonem bunyi vokal [h] sehingga kata "tambahono" menjadi kata "tambaono". Proses pengurangan fonem vokal [h] pada kata "tambahono" menjadi "tambaono" disebut proses sinkop, karena pada kata "tambahono" terjadi proses pengurangan pada tengah-tengan kata.

$$
\text { Pj : "bloso, mbak." }
$$

$\mathrm{Pb}$ : "lah kok sitek ngunu."

(kok sedikit gitu)

Kata "bloso" terjadi pengurangan fonem bunyi vokal [e] sehingga kata "beloso" menjadi kata "bloso". Proses pengurangan fonem vokal [e] pada kata "beloso" menjadi "bloso" disebut proses sinkop, karena pada kata "beloso" terjadi proses pengurangan pada tengah-tengan kata.

Pj : "Bloso sitek tok iki, gowono nyoh mbak, wolongewu wae lah, gak sah ngenyang meneh." 
(bloso sedikit saja ini, bawa saja mbak, delapan ribu, tidak usah menawar)

$\mathrm{Pb}$ : "Moh lah stik tok kok, mbak."

(tidak mau lah, sedikit gitu.)

Kata "bloso" terjadi pengurangan fonem bunyi vokal [e] sehingga kata "beloso" menjadi kata "bloso". Proses pengurangan fonem vokal [e] pada kata "beloso" menjadi "bloso" disebut proses sinkop, karena pada kata "beloso" terjadi proses pengurangan pada tengah-tengan kata.

$$
\begin{gathered}
\mathrm{Pj}: \text { :Aku duwe blanak, nduk." } \\
\text { (saya punya blanak, dek) } \\
\mathrm{Pb} \text { : "Pinten?" }
\end{gathered}
$$$$
\text { (Berapa?) }
$$

(habis-habisan ini, dua puluh lima, satu kilo lebih kok.)

Kata "blanak" terjadi pengurangan fonem bunyi vokal [e] sehingga kata "belanak" menjadi kata "blanak". Proses pengurangan fonem vokal [e] pada kata "belanak" menjadi "blanak" disebut proses sinkop, karena pada kata "belanak" terjadi proses pengurangan pada tengah-tengan kata.

$\mathrm{Pj}$ : "Srepet wes prapatan, nduk telu setengahan." (srepet sudah seperempatan, dek, tiga setengahan)

$\mathrm{Pb}$ : "Mboten lah, seng kijeng prapatan mawon. Setunggal."

(tidak lah, yang kijeng seperempatan saja, satu.)

Kata "srepet" terjadi pengurangan fonem bunyi vokal [e] sehingga kata "serepet" menjadi kata "srepet". Proses pengurangan fonem vokal [e] pada kata "serepet" menjadi "srepet" disebut proses sinkop, karena pada kata "serepet" terjadi proses pengurangan pada tengah-tengan kata.

\section{Pj : "Nemewu, nduk. Tursuwun yo, nduk."}

(enam ribu, dek. terima kasih ya, dek.)

Kata "nemewu" terjadi pengurangan fonem bunyi vokal [e] sehingga kata "enemewu" dilafalkan "nemewu". Proses penghilangan fonem vokal [e] pada kata "enemewu" menjadi "nemewu"disebut proses aferesis, karena pada kata "enemewu" terjadi proses pengurangan fonem pada awal kata. 
$\mathrm{Pb}$ : “Wak opo, mbak?"

(ikan apa, mbak?)

Kata "wak" terjadi pengurangan fonem bunyi vokal [i] sehingga kata "iwak" dilafalkan "wak". Proses penghilangan fonem vokal [i] pada kata "iwak" menjadi "wak"disebut proses aferesis, karena pada kata "iwak" terjadi proses pengurangan fonem pada awal kata.

\section{Penambahan Fonem}

Penambahan fonem pada ciri fonologi pada suatu kata berupa penambahan bunyi vokal maupun konsonan. Penambahan ini dilakukan untuk kelancaran ucapan. Penambahan fonem terlihat dalam segmen tutur berikut.

$$
\mathrm{Pj} \text { : "Mujaer mbak, mujaer" }
$$

$\mathrm{Pb}$ 1: "Mboten, de."

(tidak, de)

Kata mboten terjadi penambahan fonem vokal [m] sehingga kata boten seolah-olah terdengar mboten. Proses penambahan fonem vokal [m] pada kata boten menjadi mboten disebut proses protesis karena terjadi penambahan atau pembubuhan fonem pada tengah kata, yaitu kata boten menjadi mboten.

Penambahan fonem [m] pada kata mboten disebabkan oleh pengucapan kata dengan tempo lambat sehingga menyebabkan seolah-olah terdengar penambahan fonem [m] pada kata tersebut.

\section{$\mathrm{Pb} 2$ : "Mboten."}

(tidak)

Kata mboten terjadi penambahan fonem vokal [m] sehingga kata boten seolah-olah terdengar mboten. Proses penambahan fonem vokal [m] pada kata boten menjadi mboten disebut proses protesis karena terjadi penambahan atau pembubuhan fonem pada tengah kata, yaitu kata boten menjadi mboten.

Penambahan fonem [m] pada kata mboten disebabkan oleh pengucapan kata dengan tempo lambat sehingga menyebabkan seolah-olah terdengar penambahan fonem [m] pada kata tersebut.

\section{$\mathrm{Pj}$ : “Jagowan, nduk. Jagowan-jagowane" \\ (Jagowan, dek. Jagowan-jagowannya.)}


Kata jagowan terjadi penambahan fonem konsonan semi vokal bilabial [w] sehingga kata jagoan seolah-olah terdengar jagowan. Proses penambahan fonem konsonan [w] pada kata jagoan menjadi jagowan disebut proses epentesis karena terjadi penambahan atau pembubuhan fonem pada tengah kata, yaitu kata jagoan menjadi jagowan.

Penambahan fonem [w] pada kata jagowan disebabkan oleh pengucapan kata dengan tempo lambat sehingga menyebabkan seolah-olah terdengar penambahan fonem [w] pada kata tersebut.

\section{PENUTUP}

Ciri fonologi kata-kata yang digunakan pedagang ikan saat menjajakan ikan dagangannya menandakan adanya perubahan fonem, penghilangan fonem, dan penambahan fonem. Perubahan fonem terjadi akibat pergeseran suatu fonem pada kata misalnya kata [mujair] menjadi [mujaer] terjadi pergeseran fonem vokal [i] menjadi fonem [e]. Fonem vokal [e] pada kata [belanak] sering hilang saat diucapkan berulang-ulang menjadi [blanak]. Kata [jagoan] sering diucapkan [jagowan] terjadi penambahan fonem [w] sehingga kata jagoan menjadi [jagowan].

\section{DAFTAR PUSTAKA}

Basrowi dan Suwandi. (2008). Memahami Penelitian Kualitatif. Jakarta: Penerbit PT Rineka Cipta.

Chaer, Abdul \& Leonie Agustina. (2004). Sosiolinguistik: Perkenalan Awal. Jakarta: Penerbit PT Rineka Cipta.

Chaer, Abdul. (2009). Fonologi Bahasa Indonesia. Jakarta: Rineka Cipta.

Sugiyono. (2012). Memahami Penelitian Kualitatif. Bandung : ALFABETA. 